or placebo (table I); the serum potassium concentration showed a statistically significant decrease during treatment with chlorthalidone and chlorthalidone combined with atenolol as compared with during the atenolol or placebo period (table II); and plasma renin activity rose with chlorthalidone and decreased with atenolol, though this was not statistically significant (table II).

These findings have important implications. Beta-blockers alone are ineffective in black hypertensive patients, and thiazides rather than beta-blockers should be the baseline treatment of hypertension. When beta-blockers are used in black hypertensive patients they should initially be combined with a thiazide diuretic.

I thank Dr A J Cilliers, medical adviser, ICI South Africa (Pharmaceuticals) Limited, for support and scrupulous monitoring of the clinical data; Professor H S Schoeman, of the University of Pretoria, for analysing the statistical data; Mr A E Houlder for the plasma renin assays; and Dr P Truter, of King Edward VIII Hospital, for facilities.

\section{References}

1 Prichard BNC, Gillam PMS. Treatment of hypertension with propranolol. Br Med F 1969;i:7-16.

${ }^{2}$ Humphreys GS, Delvin DG. Ineffectiveness of propranolol in hypertensive Jamaicans. $\mathrm{Br} \mathrm{Med} \mathcal{F}$ 1968;ii:601-3.

${ }^{3}$ Grell GAC. Propranolol in black hypertensives. Br Med f 1978;ii :358.

4 Seedat YK. Propranolol in the South African non-white hypertensive patient. $S$ Afr Med $\mathcal{F} 1971 ; 45: 284-5$.

5 Wisenbaugh PE, Garst JB, Hull C, Freedman RJ, Mathews DN, Hadady M. Renin, aldosterone, sodium and hypertension. Am $\mathcal{f}$ Med $1972 ; 52$ : 175-86.

${ }^{6}$ Zacharias FJ, Cowan KJ. Comparison of propranolol and atenolol in hypertension. Postgrad Med 7 1977;53:111-3.

${ }^{7}$ Wilcox RG. Randomised study of six beta-blockers and a thiazide diuretic in essential hypertension. $\mathrm{Br}$ Med F 1978; ii :383-5.

${ }^{8}$ Seedat YK. Treatment of hypertension with the aid of beta-adrenergic blocking drugs. S Afr Med F 1975;49:845-8.

9 Baber NS, Dawes PM. $\beta$-Adrenoceptor blocking drugs and diuretics in hypertension. Br $\mathcal{F}$ Clin Pharmacol 1979;7:404.

(Accepted 16 September 1980)

\title{
Prevalence of urinary incontinence
}

\author{
THELMA M THOMAS, KAY R PLYMAT, JANET BLANNIN, T W MEADE
}

\section{Summary and conclusions}

The prevalence of urinary incontinence was investigated by determining the number of incontinent patients under the care of various health and social service agencies in two London boroughs and by a postal survey of the 22430 people aged 5 years and over on the practice lists of 12 general practitioners in different parts of the country. The prevalence of incontinence known to the health and social service agencies was $0 \cdot 2 \%$ in women and $0.1 \%$ in men aged $15-64$ and $2.5 \%$ in women and $1.3 \%$ in men aged 65 and over. The postal survey, to which $89 \%$ of the people whose correct address was known replied, showed a prevalence of urinary incontinence of $8.5 \%$ in women and $1.6 \%$ in men aged 15-64 and $11.6 \%$ in women and $6.9 \%$ in men aged 65 and over. Nulliparous women had a lower prevalence than those who had had one, two, or three babies, but within the parity range of one to three there were no differences in prevalence. The prevalence was appreciably increased in women who had had four or more babies. Incontinence was moderate or severe in a fifth of those who reported it in the postal survey, of whom less than a third were receiving health or social services for the condition.

Incontinence is a common symptom, and many unrecognised cases appear to exist. There may be considerable scope for improving its management.

MRC Epidemiology and Medical Care Unit, Northwick Park Hospital, Harrow, Middlesex

THELMA M THOMAS, MB, MRCP, member of clinical scientific staff

KAY R PLYMAT, MSN, nurse practitioner (present position: family nurse practitioner, Fairfield Family Medical Center, Winnsboro, S Carolina, USA)

T W MEADE, BM, FRCP, director

Clinical Investigation Unit, Ham Green Hospital, Bristol

JANET BLANNIN, SRN, research sister

\section{Introduction}

Although interest is growing in the investigation, treatment, and management of incontinence, its prevalence in the general population has so far been based on estimates made in selected groups of people of different ages. ${ }^{1-11}$ We therefore studied the prevalence of urinary incontinence in those aged 5 and over in different areas in England and Wales.

\section{Methods \\ We considered incontinence as "recognised" or "unrecognised." Those with recognised incontinence were patients known to the various health and social service agencies participating in their management. Unrecognised incontinence referred to those identified by a study in the general population. Our definition of "regular" urinary incontinence was involuntary excretion or leakage of urine in inappropriate places or at inappropriate times twice or more a month, regardless of the quantity of urine lost.}

\section{RECOGNISED INCONTINENCE}

This part of the study was carried out in the London boroughs and health districts of Brent and Harrow. The relevant agencies were provided with the survey definition of incontinence and asked to provide the age, sex, address, and details of the type of incontinence (urine or faeces, or both) in the patients under their care. We received notifications from each agency for a year between 1976 and 1979, not all agencies coming into the study at the same time. The sources concerned included community nurses, old people's homes, geriatric wards of two district general hospitals, long-stay geriatric wards, psychiatric wards, hospitals and homes for the mentally handicapped, day centres, the Multiple Sclerosis Society, Spina Bifida Society, ordinary and special schools, and the pad and laundry services. We confined this study of recognised incontinence to people aged 15 and over. As the London boroughs of Brent and Harrow are not coterminus with the health districts we used population estimates for both to define a total borough and health district population, ${ }^{12}$ which we used to calculate the prevalence of recognised incontinence in different age and sex groups. 


\section{UNRECOGNISED INCONTINENCE}

Unrecognised incontinence was studied by means of a postal questionnaire sent to all those aged 5 or more on the lists of 12 general practitioners in Harrow, Harlesden, Wembley, Bristol, and south Wales (total population 22430 ). The general practitioners sent letters to each of their patients aged 16 and over, explaining the study and asking them to complete the questionnaire. Parents were asked to fill in forms for children aged 5-15. Up to two reminders were sent at three-weekly intervals to those who did not reply initially. Those who did not want to take part were asked to return a blank form.

The questions asked enabled answers to be interpreted in terms of the survey definition of incontinence. Questions on stress incontinence, urge incontinence, and bedwetting were included, together with a question on faecal incontinence. An additional category of "occasional incontinence" was also included-that is, incontinence occurring less than twice a month. A pilot study had established that this category could be accurately distinguished from regular incontinence. Patients were classified as "never incontinent," "occasionally incontinent," or "regularly incontinent." Patients whose replies were unclear or ambiguous were classified as uncertain. Women were asked how many babies they had had.

To validate the questionnaire the 237 adults in Wembley and one practice in south Wales who reported regular incontinence were asked by their general practitioners to agree to interview by one of the survey team nurses. We did not consider it reasonable to interview any of those reporting no incontinence. At interview the severity of incontinence was also assessed. Four categories were defined: Minimal: No extra laundry; no pads or expenses; no restriction in activities because of incontinence. Slight: Very small amount of extra laundry; pads worn only occasionally; no restriction in activities. Moderate: Extra laundry or pads or expenses; some restriction in activities. Severe: Extra laundry or pads or expenses; activities restricted; required help from others.

\section{Results}

\section{RECOGNISED INCONTINENCE:}

During the period of contact with the health and social service agencies in Brent and Harrow we received notifications of 276 women and 140 men aged 15-64, including 104 women and 67 men in institutions. A total of 1147 women and 381 men aged 65 and over were notified, of whom 586 women and 145 men were in institutions. We estimated the total population of the study area to be 150000 women and 135000 men aged 15-64 and 45000 women and 29000 men aged 65 and over. The prevalence of incontinence was thus $0.2 \%$ in women and $0.1 \%$ in men aged $15-64$ and $2.5 \%$ in women and $1.3 \%$ in men aged 65 and over. If the incontinent patients in long-stay institutions are excluded the prevalence is about $0.1 \%$ in women and $0.05 \%$ in men aged 15-64, and $1.2 \%$ in women and $0.8 \%$ in men aged 65 and over.

\section{UNRECOGNISED INCONTINENCE}

Replies were received from $18084(89 \%)$ of the 20398 patients who had not moved from the address shown on the practice record. An additional $390(1.9 \%)$ refused to take part. The response rate varied between the practices, being lowest in Harlesden $(80 \%)$ and highest in south Wales $(95 \%)$. The results from the different areas were closely similar and were therefore combined.

Tables I, II show the results by age for the men and women res-

TABLE I-Prevalence of urinary incontinence in men. (Figures are numbers ( \%) of respondents in each age group)

\begin{tabular}{lccccc}
\hline Age (years) & $\begin{array}{c}\text { Never } \\
\text { incontinent }\end{array}$ & $\begin{array}{c}\text { Occasional } \\
\text { incontinence incontinence }\end{array}$ & $\begin{array}{c}\text { Regular } \\
\text { Uncertain }\end{array}$ & Total \\
\hline $5-14$ & $1367(81 \cdot 2)$ & $184(10 \cdot 9)$ & $116(6 \cdot 9)$ & $17(1 \cdot 0)$ & $1684(100)$ \\
$15-24$ & $1267(95 \cdot 4)$ & $28(2 \cdot 1)$ & $19(1 \cdot 4)$ & $14(1 \cdot 1)$ & $1328(100)$ \\
$25-34$ & $1146(94 \cdot 7)$ & $34(2 \cdot 8)$ & $10(0 \cdot 8)$ & $20(1 \cdot 7)$ & $1210(100)$ \\
$35-44$ & $1161(93 \cdot 8)$ & $31(2 \cdot 5)$ & $18(1 \cdot 5)$ & $28(2 \cdot 3)$ & $1238(100)$ \\
$45-54$ & $1096(93 \cdot 3)$ & $43(3 \cdot 7)$ & $19(1 \cdot 6)$ & $17(1 \cdot 4)$ & $1175(100)$ \\
$55-64$ & $909(88 \cdot 8)$ & $58(5 \cdot 7)$ & $30(2 \cdot 9)$ & $27(2 \cdot 6)$ & $1024(100)$ \\
$65-74$ & $637(80 \cdot 6)$ & $66(8 \cdot 4)$ & $48(6 \cdot 1)$ & $39(4 \cdot 9)$ & $790(100)$ \\
$75-84$ & $206(75 \cdot 5)$ & $26(9 \cdot 5)$ & $22(8 \cdot 1)$ & $19(7 \cdot 0)$ & $273(100)$ \\
$\geqslant 85$ & $27(69 \cdot 2)$ & $1(2 \cdot 6)$ & $6(15 \cdot 4)$ & $5(12 \cdot 8)$ & $39(100)$ \\
\hline \multicolumn{1}{c}{ Total } & $7816(89 \cdot 2)$ & $471(5 \cdot 4)$ & $288(3 \cdot 3)$ & $186(2 \cdot 1)$ & $8761(100)$ \\
\hline
\end{tabular}

TABLE II-Prevalence of urinary incontinence in women. (Figures are numbers $(\%)$ of respondents in each age group)

\begin{tabular}{lrrrrr}
\hline Age (years) & $\begin{array}{c}\text { Never } \\
\text { incontinent }\end{array}$ & $\begin{array}{c}\text { Occasional } \\
\text { incontinence }\end{array}$ & $\begin{array}{c}\text { Regular } \\
\text { incontinence }\end{array}$ & Uncertain & Total \\
\hline $5-14$ & $1284(82 \cdot 5)$ & $175(11 \cdot 2)$ & $80(5 \cdot 1)$ & $17(1 \cdot 1)$ & $1556(100)$ \\
$15-24$ & $1065(82 \cdot 5)$ & $154(11 \cdot 9)$ & $52(4 \cdot 0)$ & $20(1 \cdot 5)$ & $1291(100)$ \\
$25-34$ & $949(72 \cdot 2)$ & $263(20 \cdot 0)$ & $72(5 \cdot 5)$ & $31(2 \cdot 4)$ & $1315(100)$ \\
$35-44$ & $816(66 \cdot 5)$ & $254(20 \cdot 7)$ & $125(10 \cdot 2)$ & $32(2 \cdot 6)$ & $1227(100)$ \\
$45-54$ & $771(63 \cdot 9)$ & $264(21 \cdot 9)$ & $142(11 \cdot 8)$ & $29(2 \cdot 4)$ & $1206(100)$ \\
$55-64$ & $777(66 \cdot 6)$ & $217(18 \cdot 6)$ & $139(11 \cdot 9)$ & $33(2 \cdot 8)$ & $1166(100)$ \\
$65-74$ & $733(73 \cdot 2)$ & $146(14 \cdot 6)$ & $88(8 \cdot 8)$ & $34(3.4)$ & $1001(100)$ \\
$75-84$ & $288(63 \cdot 2)$ & $62(13 \cdot 6)$ & $73(16 \cdot 0)$ & $33(7 \cdot 2)$ & $456(100)$ \\
85 & $64(61 \cdot 0)$ & $17(16 \cdot 2)$ & $17(16 \cdot 2)$ & $7(6 \cdot 7)$ & $105(100)$ \\
\hline Total & $6747(72 \cdot 4)$ & $1552(16 \cdot 6)$ & $788(8 \cdot 5)$ & $236(2 \cdot 5)$ & $9323(100)$ \\
\hline
\end{tabular}

pectively. (These results include those doubly incontinent. The results for people with only faecal incontinence will be reported elsewhere; in terms of urinary incontinence they were classified in this study as never incontinent.) Although low in men aged 15-64, the prevalence of regular incontinence increased with increasing age after 35 . Abou $90 \%$ of the incontinent boys aged 5-14 had nocturnal enuresis; of the incontinent girls in this age range only $60 \%$ were bedwetters, the remainder complaining mainly of urge incontinence. Incontinence, whether regular or occasional was more common in women than men at all ages except 5-14 years. The prevalence in women changed little between the ages of 35 and 64 but fell in those aged 65-74 and rose in those aged 75 and over.

The figure shows the results for women in different age groups according to parity. The results for women aged 15-24 who had had three or more babies were omitted because of the small numbers. A further 239 women were omitted because their parity was not known. Incontinence was reported less commonly by nulliparous than parous women at all ages but, except in the age group 45-54, was no more common in those who had had two or three babies than in those who had had only one. Women who had had four or more babies were most likely to report regular incontinence.

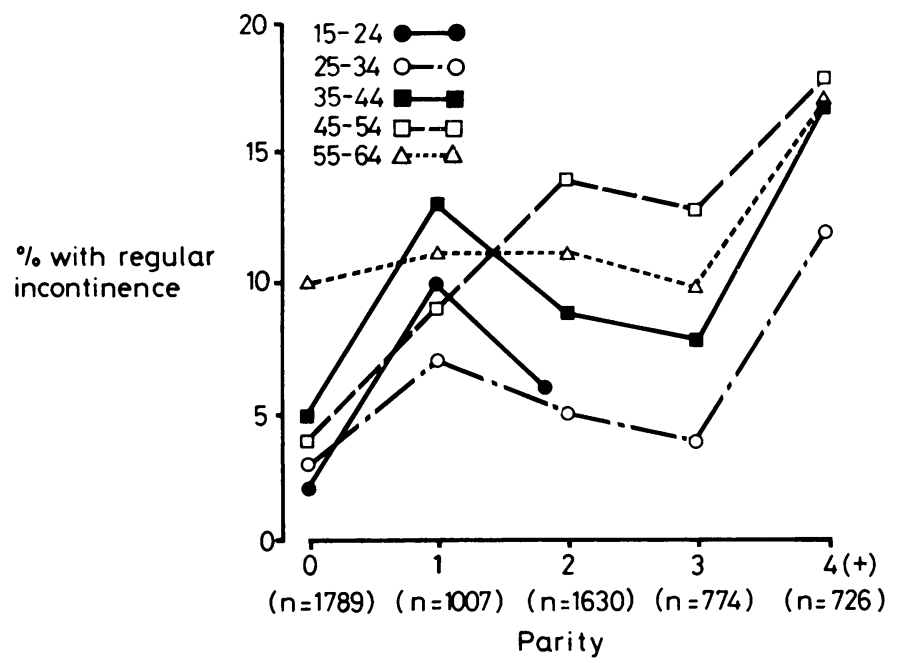

Prevalence in women of regular incontinence $(\%)$-that is, people incontinent twice or more per month-by age and parity.

Altogether $178(75 \%)$ of the 237 adults approached were interviewed. Table III shows the numbers whose incontinence was confirmed at interview four to eight months after the postal survey. Twenty $(11 \%)$ were not incontinent: 10 had had temporary causes of incontinence, three were incontinent only occasionally, and seven had apparently made a mistake in completing the form. Table IV shows the severity of incontinence in those interviewed and the numbers who were not receiving help from the district nurse, health visitor, social worker, pad service, or laundry service. Thus, of the 158 people still incontinent when interviewed, only $16(10 \cdot 1 \%)$ were in touch with these services. Twenty-four $(70.6 \%)$ of the 34 with moderate or severe incontinence were receiving no help from these services. Most of this group found their incontinence an embarrassing problem; most had 
TABLE III-Replies at interview by age and sex

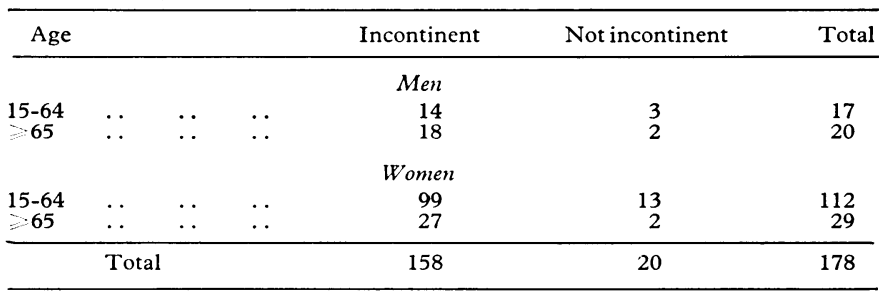

TABLE IV-Severity of urinary incontinence at interview by age and sex (numbers of patients not receiving help from community nurses, social workers, or pad or laundry services shown in parentheses)

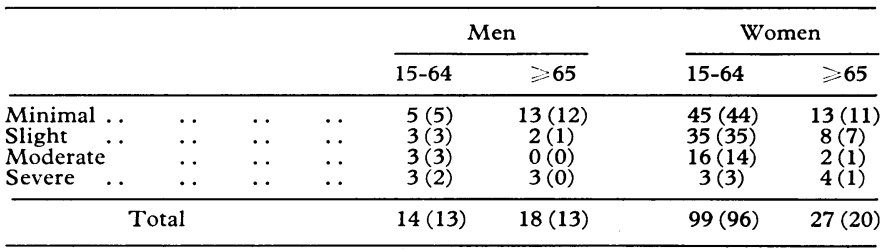

not sought help from the services mentioned above. Few of those with minimal or slight incontinence considered that they had a problem requiring medical attention.

\section{Discussion}

Estimates of the prevalence of incontinence depend on the definition used and the population studied. Our definition of regular incontinence as two or more episodes occurring in the past month was chosen on the assumption that it would detect incontinence of a frequency to be an important problem to the person concerned and would exclude short-term episodes (for example, during an acute illness). The definition proved easy to apply both in the postal questionnaire and for the agencies notifying recognised cases. We made no comprehensive attempt to gauge the quantity of urine lost, although most of those with minimal or slight incontinence volunteered that they lost only small quantities. One group not covered by our definition was those patients who would have been incontinent were they not being well managed-for example, those who were chairbound but had a reliable means of transferring to the lavatory.

About $12 \%$ of those who recorded regular incontinence in the postal questionnaire were probably not incontinent, judged by our findings in the sample interviewed. We did not think it reasonable to estimate the rate of false-negative replies, which would have entailed interviewing very large numbers.

The prevalence found in children aged 5-14 did not differ appreciably from that reported by others, ${ }^{1}$ and the differences may largely be explained by differences in definition.

Osborne $^{5}$ reported a prevalence of troublesome stress incontinence of $26 \%$ in a sample of women aged 35-60. Brocklehurst et $a l^{6}$ reported a figure of $57 \%$ in a sample of women aged 45-64. Other studies ${ }^{2}{ }^{3}$ have suggested that $50 \%$ of nulliparous young women have stress incontinence. The proportion of women in our study reporting any incontinence whether regular or occasional is lower than that in other studies. Only $5 \%$ of those aged 15-34 reported regular incontinence, and about $10 \%$ of those aged 35-64. Between the ages of 35 and 64 there was no change in the overall prevalence of regular incontinence. Stress incontinence was reported more commonly in those aged 45 to 54, however, while urge incontinence increased with age between 35 and 64 . The lower prevalence of regular incontinence in the 65-74 age range reflects a further decrease in the prevalence of stress incontinence. This decrease with age has been reported by others. ${ }^{\circ}$

Urinary incontinence is generally believed to be associated with parity. Nulliparous women in our study reported incontinence least often: there was a higher prevalence in those who had had one, two, or three babies than in the nulliparous but no difference within this parity range. The prevalence was appreciably higher, however, in those who had had four or more babies.

Our findings in the elderly are similar to those reported by others, ${ }^{8-10}$ especially when those with occasional incontinence are included. Prevalence increased appreciably after the age of 75 in women but not in men.

Of the 158 people with incontinence who were interviewed, $34(22 \%)$ had moderate or severe incontinence. Only 10 of these were receiving health or social services for their incontinence. It does not necessarily follow that all these patients needed or would have been helped by such services. Our findings as a whole suggest, however, that regular incontinence is common, particularly in some sections of the population, and that there may be considerable scope for improving its management, especially in those with moderate or severe incontinence.

The estimates of the prevalence of incontinence obtained from the postal survey were much greater than those obtained from the survey of recognised incontinence. If only those people identified through the postal survey and in touch with the services mentioned above are considered (table IV) the figures are $0.2 \%$ for women and $0 \cdot 1 \%$ for men aged $15-64$ and $3 \%$ for women and $1.9 \%$ for men aged 65 and over. These are still higher than the estimates from the figures for recognised incontinence in patients not in long-term institutions. This might be due to underreporting of recognised incontinence or might reflect the selected nature of the practices participating in the postal survey, where the level of services received by incontinent patients may be greater than in other practices.

We wish to thank Drs F Hicks, J T Hart, S G Hill, K M Townend, E M Townend, I A Hawkins, J Du Heaume, R Law, R R Law, P G Brent, D A Coffman, and E Magill and staff for participating in this study; and Dr O Samuel, Dr R Williams, the interviewers in south Wales and Wembley, and the staff at the clinical investigation unit, Ham Green Hospital, Bristol, for their work. We also thank Dr W R S North and Anne Walgrove for their help with the data. The study was assisted by a grant from the Department of Health and Social Security.

\section{References}

${ }^{1}$ Rutter M, Yule W, Graham P. Enuresis and behavioural deviance: some epidemiological considerations. In: Kolin I, MacKeith RC, eds. Bladder control and enuresis. London: Heinemann, 1973: 137-47. (Clinics in Developmental Medicine Nos 48/49.)

2 Wolin LH. Stress incontinence in young healthy nulliparous female subjects. F Urol 1969;101:545-9.

${ }^{3}$ Nemir A, Middleton RP. Stress incontinence in young nulliparous women. Am $\mathcal{F}$ Obstet Gynecol 1954;68:1166-8.

${ }^{4}$ Crist T, Shingleton HM, Koch GG. Stress incontinence and the nulliparous patients. Obstet Gynecol 1972;40:13-7.

5 Osborne JL. Post-menopausal changes in micturition habits and in urine flow and urethral pressure studies. In: Campbell S, ed. The management of the menopause and post-menopausal years. Lancaster: MTP, 1976: 285-9.

${ }^{6}$ Brocklehurst JC, Fry J, Griffiths LL, Kalton G. Urinary infection and symptoms of dysuria in women aged 45-65 years: their relevance to similar findings in the elderly. Age Ageing 1972;1:41-7.

7 Knox JDE. Ambulant incontinent patients in general practice. A survey to ascertain the prevalence of these patients and their distribution by type of practice. Nursing Times 1979;75:1683.

${ }^{8}$ Brocklehurst JC, Dillane JB, Griffiths L, Fry J. The prevalence and symptomatology of urinary infection in an aged population. Gerontology $1968 ; 10: 242-53$.

${ }^{9}$ Milne JS, Williamson J, Maule MM, Wallace ET. Urinary symptoms in older people. Modern Geriatrics $1972 ; 2: 198-212$.

10 Yarnell JWG, StLeger AS. The prevalence, severity and factors associated with urinary incontinence in a random sample of the elderly. Age Ageing $1979 ; 8: 81-5$.

11 Isaacs B, Walkey FA. A survey of incontinence in elderly hospital patients. Gerontology $1964 ; 6: 367-76$.

12 North-west Thames Regional Health Authority, Statistics and Health Information Section. Population estimates for 1978. London: North-west Thames Regional Health Authority, 1979. (Population paper 5.)

(Accepted 5 September 1980) 